\title{
Parameter Estimation Technique of Nonlinear Prosthetic Hand System
}

\author{
M.H.Jali ${ }^{1, \mathrm{a}}$, N.A.Rashid ${ }^{2, \mathrm{~b}}$, R.Ghazali ${ }^{3, \mathrm{c}}$, T.A.Izzuddin ${ }^{4, \mathrm{~d}}$, E.S.A.Aziz ${ }^{\mathrm{e}}$ \\ $1,2,3,4,5$ Rehabilitation Engineering and Assistive Technology Research Laboratory \\ Advanced Control Research Laboratory, Robotics and Industrial Automation Research Group (RIA) \\ Centre for Robotics and Industrial Automation (CeRIA), Faculty of Electrical Engineering (FKE) \\ Universiti Teknikal Malaysia Melaka (UTeM), Malaysia \\ mohd.hafiz@utem.edu.mya ,nadiaabdrashid@ymail.com ${ }^{\mathrm{b}}$,rozaimi.ghazali@utem.edu.my ${ }^{\mathrm{c}}$, \\ tarmizi@utem.edu.my ${ }^{\mathrm{d}}$,ellyanaaziz@gmail.com ${ }^{\mathrm{e}}$
}

\begin{abstract}
This paper illustrated the parameter estimation technique of motorized prosthetic hand system. Prosthetic hands have become importance device to help amputee to gain a normal functional hand. By integrating various types of actuators such as DC motor, hydraulic and pneumatic as well as mechanical part, a highly useful and functional prosthetic device can be produced. One of the first steps to develop a prosthetic device is to design a control system. Mathematical modeling is derived to ease the control design process later on. This paper explained the parameter estimation technique of a nonlinear dynamic modeling of the system using Lagrangian equation. The model of the system is derived by considering the energies of the finger when it is actuated by the DC motor. The parameter estimation technique is implemented using Simulink Design Optimization toolbox in MATLAB. All the parameters are optimized until it achieves a satisfactory output response. The results show that the output response of the system with parameter estimation value produces a better response compare to the default value
\end{abstract}

Keyword- Parameter estimation, Prosthetic hand, Lagrangian equation, Dynamic modeling

\section{INTRODUCTION}

Research on the prosthetic hand control system has been extensively studied since the seventies. The system becomes more complicated due to numbers of motors, gears and linkage cables are required to drive all the fingers that would cause unexpected disturbance appear within the system. Prosthetic hand is divided to three parts of finger considering one dimension that has similarity with the compound pendulum. Human finger movement can be model using Lagrangian motion equation similar to the compound pendulum by considering the linearity. To imitate the functionality and motion characteristics of the real human hand, biomimetic studies of the human hand has become important [1]. In several studies, biomechanical models of the human hand fingers have been developed for determining the kinematical and dynamical behaviour of hands and fingers.

Prosthesis has become one of the essential tools to replace the lost limb's physiological appearance. It could restore some of the normal functional limb that was lost due to war, congenital conditions and accidents. In addition, the interchangeable prosthesis that only been used when needed has attract a lot of researcher to explore in this field. A lot of effort to develop a prosthesis that could emulate the real human hand has been conducted in term of function, psycho-spiritual sense and cosmetic appearance. One of the most important criteria for an effective prosthetic device is the control quality. Even though numerous studies have been conducted to improve the prosthetic control, it still substantial difference in term of control quality between the prosthetic hand and real human hand. Recent survey shows that amputees need more life-like manner functional prosthetic hand and more intuitive controlled [2].

Mathematical modeling is treated as pre-develop phase before the control approach is applied to the real hardware device. There are several well-known approaches such as Lagranges's equation, Newton-Euler method Kane's approach and forward recursive formulation. Mathematical modeling is not simply an easy task. It composed the application of numerous mathematical rule in order to derive an appropriate equation. This paper will first show the simulation model of linear and nonlinear prosthetic finger. Subsequently, the parameter estimation based on Simulink Design Optimization method is performed for both linear and nonlinear model to obtain a highly accurate parameter for the model. Finally, the parameter estimated is integrated with PID controller to observe the performance of the model before and after optimization.

\section{Methodology}

\section{A. Simulation Model of Linear and Nonlinear Prosthetic Finger Movement System}

This part describes the result from the Euler Lagrange that need to be simulate in order to see the data response. By using Simulink in MATLAB software the equation from Euler Lagrange can be identify to be usable or not. Fig. 1 shows the subsystem in block diagram of the Prosthetic Finger System. This part describes the result from the Euler Lagrange that need to be simulate in order to see the data response. By using Simulink in MATLAB 
software the equation from Euler Lagrange can be identify to be usable or not. Fig. 1 shows the subsystem in block diagram of the Prosthetic Finger System.

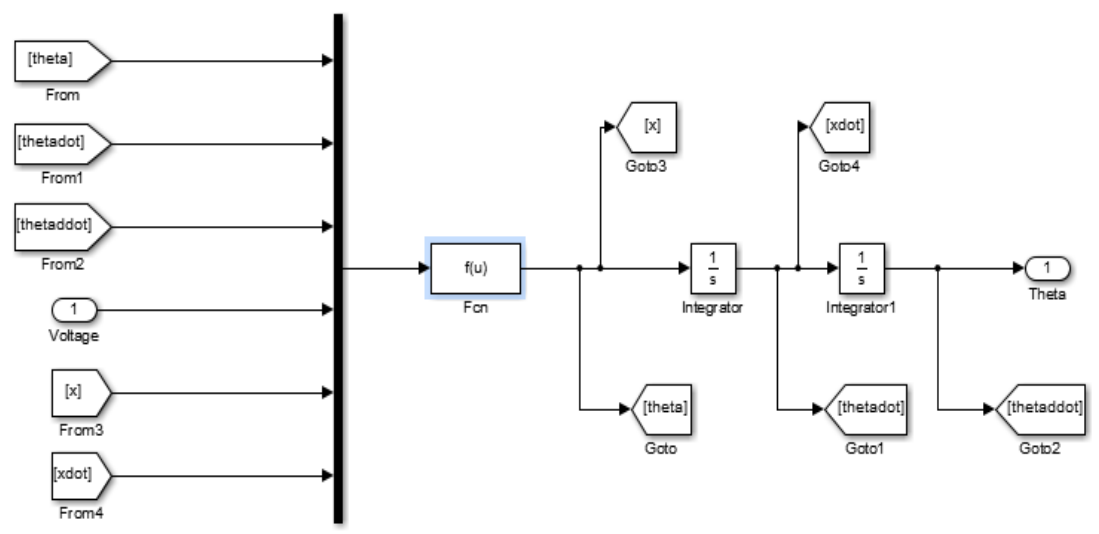

Fig. 1 Subsystem in block diagram of the Prosthetic Finger System

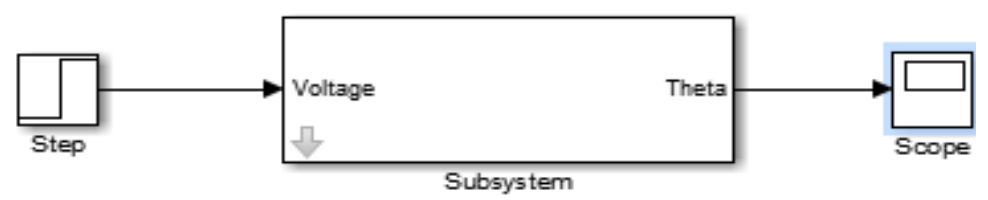

Fig. 2 Block diagram of Prosthetic finger System simulated in Simulink

Fig. 2 shows the Simulink block diagram of the system. The parameter in linear finger movement that implement in MATLAB shows in Fig. 6 [3]. The control parameter of the system is a position/ theta. The specifications of payload which will be used in finger movement system are described in Fig. 3. From the figure of subsystem, it shows that the voltage as the input and position/theta as the output. All the parameter has been tabulated in Table 1 and is set as in Fig. 4. Step input is applied as an input voltage and it has been set as 1 Volts. The step input signal is representing as the supply to operate movement of finger. Step input is the time behavior of the output of a general system when its input changes from zero to one in a very short time. The performance of finger movement system is analyzed.

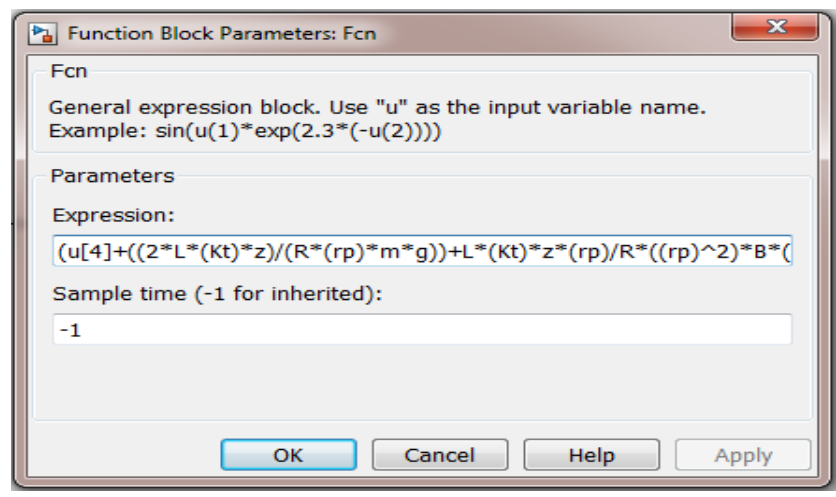

Fig. 3 Expression Block in MATLAB 
Table 1 List of Parameters

\begin{tabular}{|c|c|c|}
\hline Parameters & Unit & Values \\
\hline Resistance & $\mathrm{R}$ & $2.6 \Omega$ \\
\hline Constant torque & $\mathrm{Kt}$ & $0.007 \mathrm{NmA}^{-1}$ \\
\hline Constant electric & $\mathrm{Ke}$ & $0.007 \mathrm{Vsrad}^{-1}$ \\
\hline Gear ratio & $\mathrm{z}$ & 15 \\
\hline Radius pulley & $\mathrm{rp}$ & $0.02 \mathrm{~m}$ \\
\hline Length & $\mathrm{L}$ & 0.75 \\
\hline Mass & $\mathrm{m}$ & 1 \\
\hline Gravity & $\mathrm{g}$ & 9.81 \\
\hline Friction & $\mathrm{B}$ & 12.32 \\
\hline
\end{tabular}

\begin{tabular}{l} 
Fa. Function Block Parametersi Subsystem \\
Parameters \\
resistance \\
\hline 2.9 \\
constant torque \\
0.007 \\
constant electric \\
\hline 0.007 \\
gear ratio \\
\hline 15 \\
radius pulley \\
\hline 0.02 \\
length \\
\hline 0.75 \\
mass \\
\hline 1 \\
gravity \\
\hline 9.81 \\
friction \\
\hline
\end{tabular}

Fig. 4 Parameters that implement in Simulink

B. Simulink Design Optimization (Parameter estimation)

Simulink Design Optimization (Parameter Estimation) is the method to estimate and optimize the output of plant system approximate with the real data output response as shown in Fig. 5. The non-linear plant system is preferable because the linear plant system will eliminate some variable from the original equation

In order to estimate any real value of plant system, datasheet motor is important instead of mathematical formula to find the default value [4]. As an example, in this experiment is to find torque constant (Kt), torque electric $(\mathrm{Ke})$, gear $\operatorname{ratio}(\mathrm{z})$ and $\operatorname{resistance}(\mathrm{R})$ by using this method. Parameter estimation is a method to get the limit/range of parameter that no declare by the manufacturer.

At the end of this method, after several iteration as shown in Fig. 6, the output response of the plant based on the parameter estimation value is compared with the real data output response to check the validity of the value 


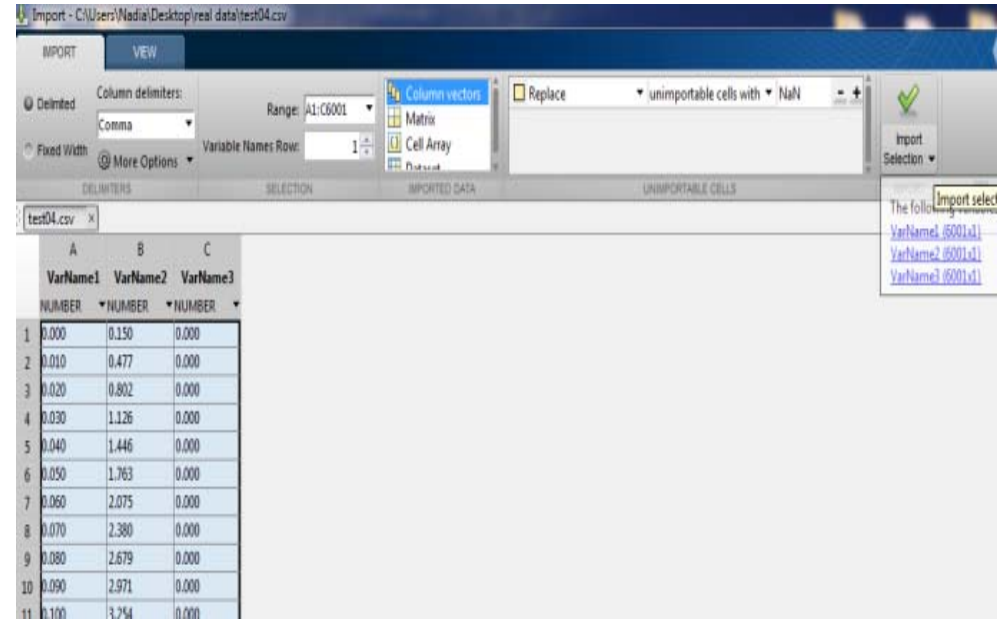

Fig. 5 The Real Data were import into the workspace

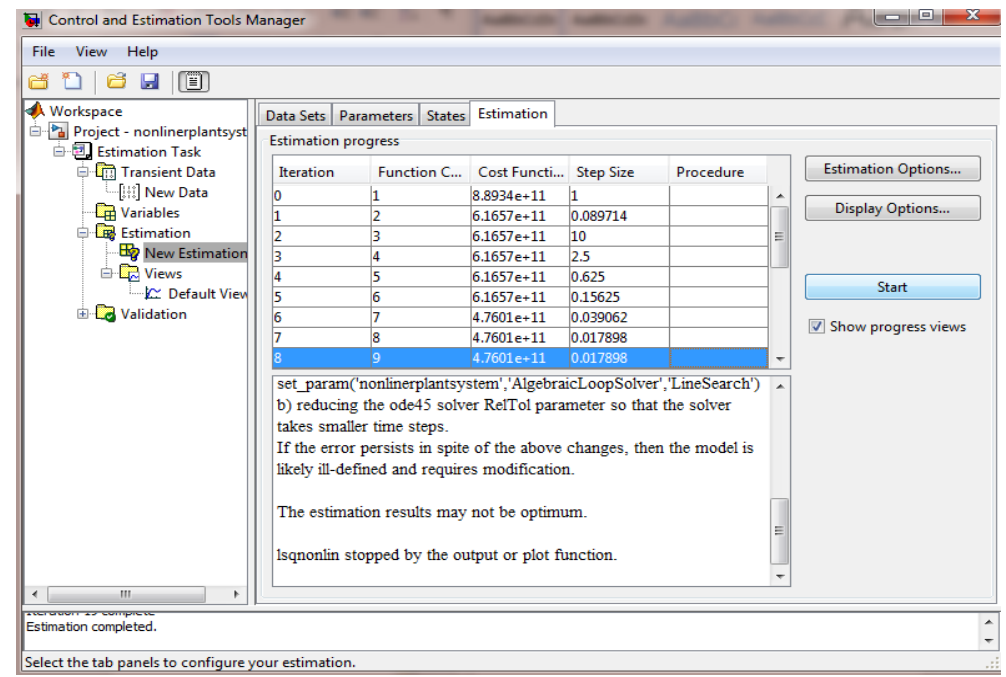

Fig. 6 The result of iteration will appeared

\section{RESULTS AND DISCUSSION}

A. Euler Lagrange of Nonlinear Output Response

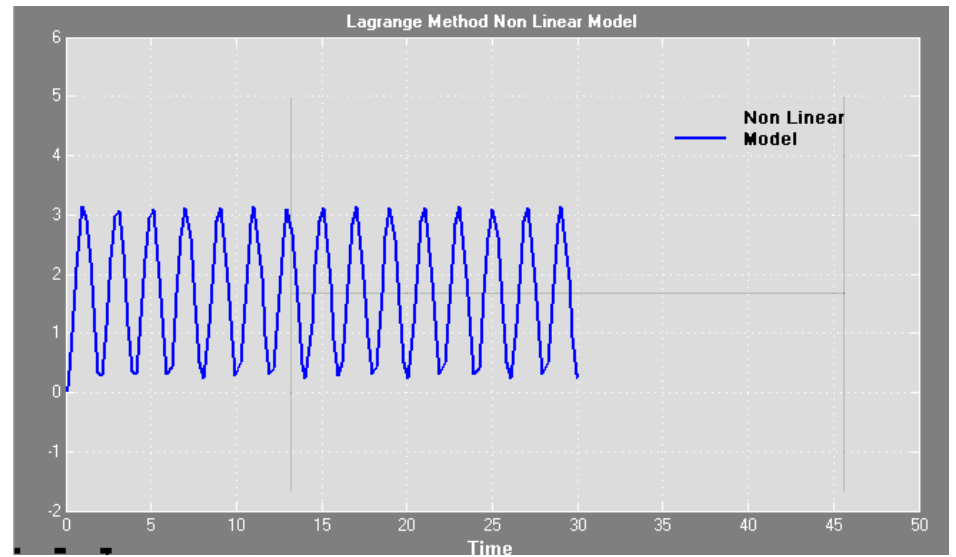

Fig. 7 Euler Lagrange Nonlinear Output Responses

In some cases, linearization of a nonlinear system is normally obtainable by using Jacobian matrix equilibrium point. Then, by using the linearized system, a simple linear controller can be applied to achieve stabilization. However, the controller will not be able to guarantee stabilization beyond the wide range of non-linear sector. The contradiction between the actual non-linear system and its linearized version would devise a cunning test to control engineers. In fact, stabilizing task becomes difficult when non-linearity is to taken into consideration and 
linearization model of such system is omitted. The contradiction between the actual non-linear system and its linearized version in Fig. 7 would devise a cunning test to control engineers. The difference between linear and non-linear output responses caused by the certain parameter that have been eliminated during the linearization such as sin theta will be cancelled out from the equation because the value is too small and cos theta will be turned to one because the linearization condition.

B. Estimation Parameter Nonlinear Plant System

In this research, the output of a nonlinear response of plant system is position / theta. Only real output position data response was taken to compare with the non-linear parameter and optimized the unknown value parameter. Fig. 8 shows the real data form the system identification process that is fed into the Simulink design optimization toolbox.

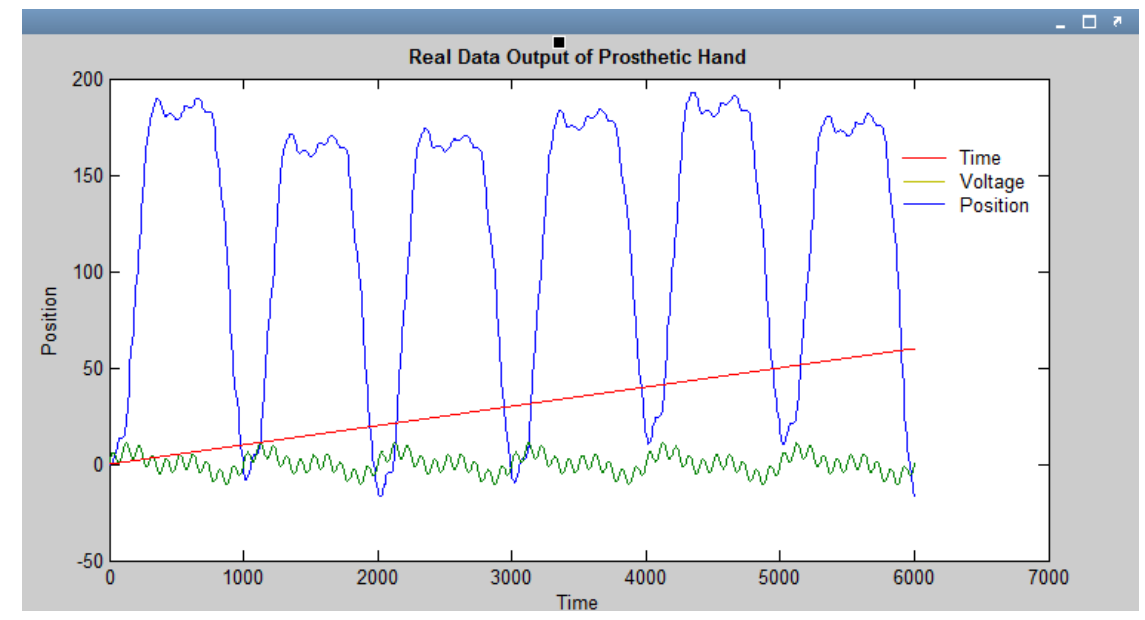

Fig. 8 Time, Voltage, Position Output Response

The unknown parameter value such as Torque Constant (Kt), Torque Electric (Ke), Gear ratio (z), and Resistance(R) were the unknown parameter in the non-linear plant system. By using optimization parameter, each of the values can be automatically discovered. Fig. 9 shows the trajectories of estimating parameters process from the measured data (non-linear plant system) approximate with real output response data. Figure 10 shows the measured and simulated output response of the system.

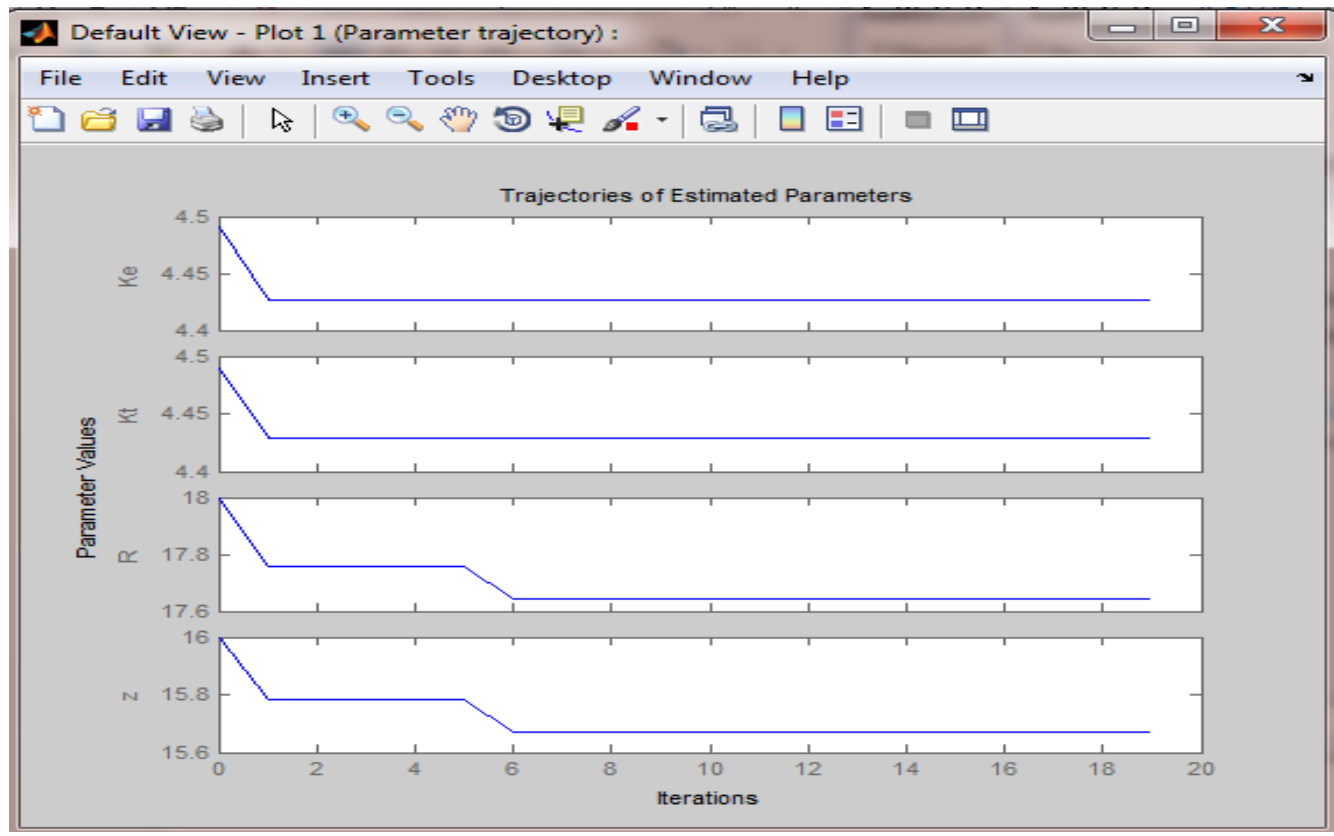

Fig. 9 Trajectories of Kt, Ke, R, and $\mathrm{z}$ of estimated parameter 


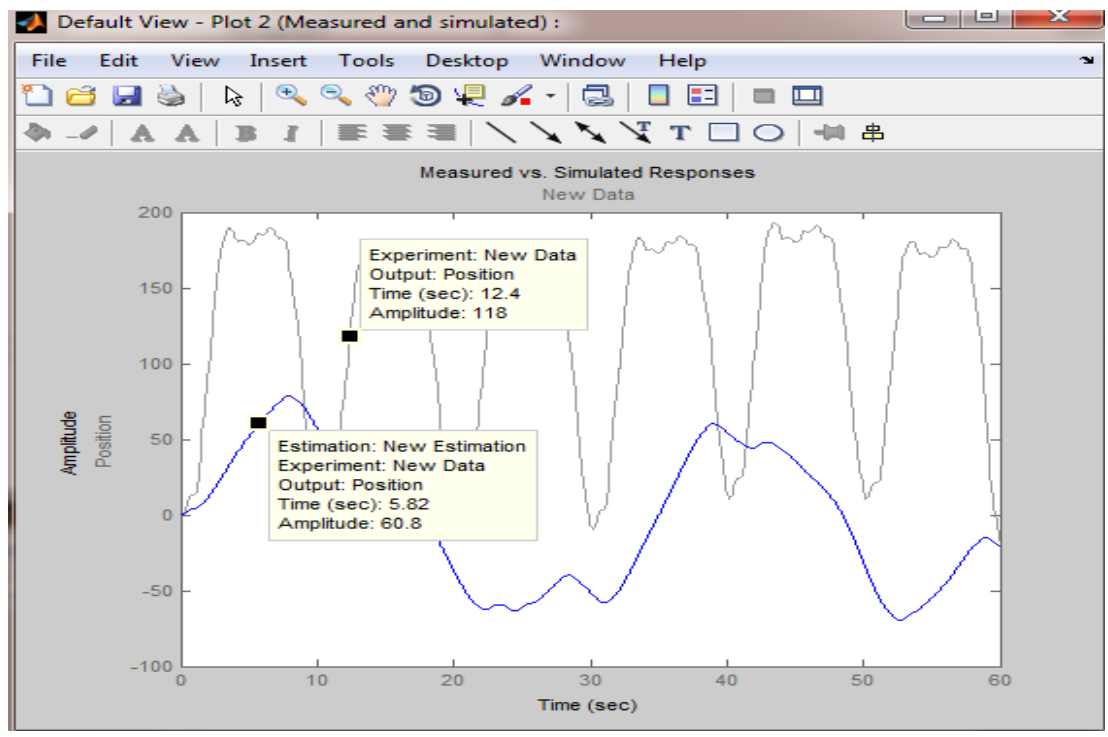

Fig. 10 Result of Non-linear and real data Position Output Response

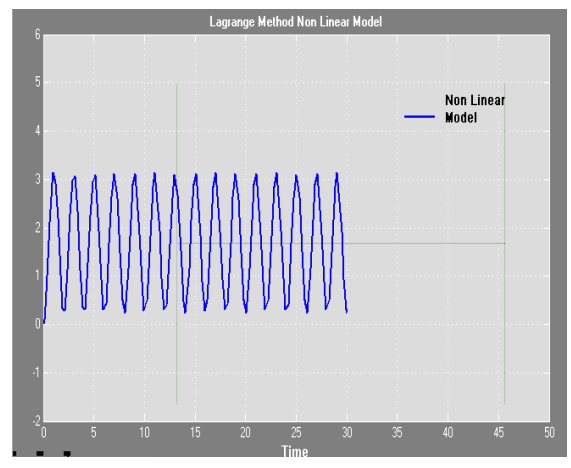

Fig. 11 Position Output before optimization

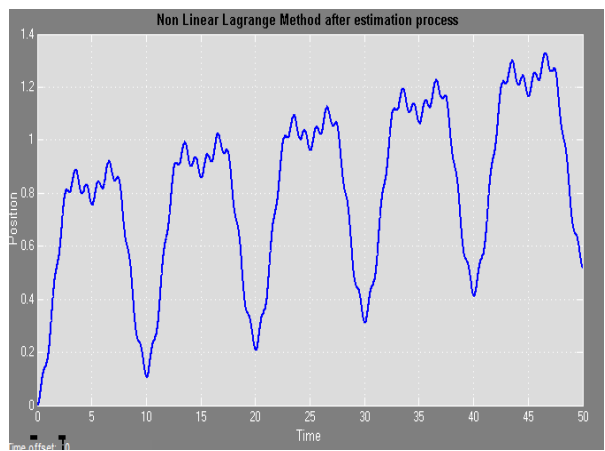

Fig. 12 Position Output after optimization

Fig. 11 shows the position output response before optimization using estimation parameter and Fig. 12 shows the output response after optimization. The result after the optimized process shows similar output position approximate with the real data position output response.

C. Euler Lagrange Nonlinear Plant System with PID

The P, I and D terms need to be "tuned" to suit the dynamics of the process being controlled. Any of the terms described above can cause the process to be unstable, or very slow to control, if not correctly set. These days temperature control using digital PID controllers have automatic auto-tune functions. During the auto-tune period the PID controller controls the power to the process and measures the rate of change, overshoot and response time of the plant [5]. Fig. 13 shows the PID controller performance with the optimized parameter estimation values. It shows acceptable response compare to the previous paramater values.

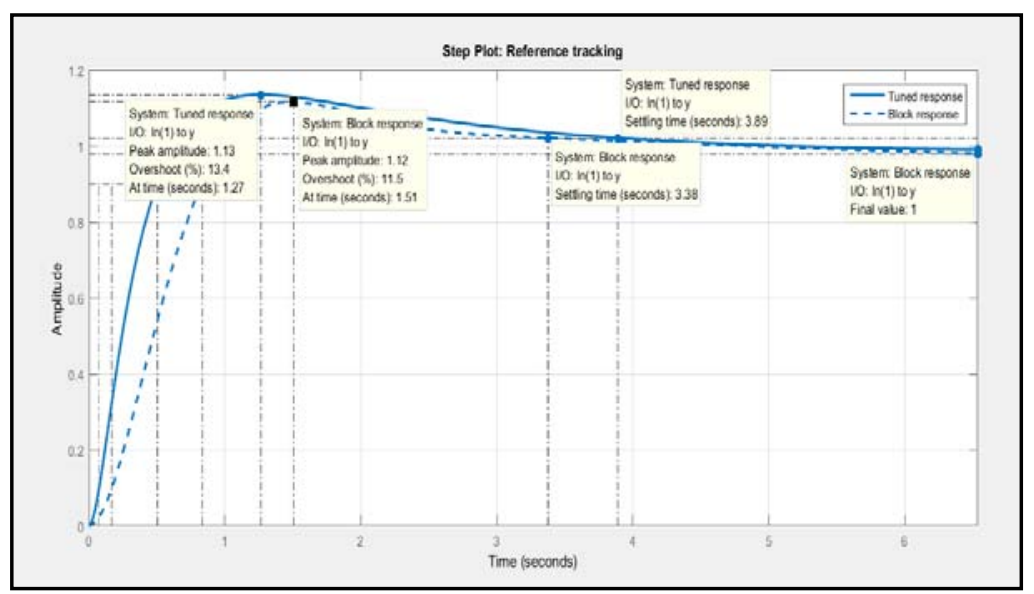

Fig. 13 PID Controller performance result 
Table 2 Comparison of the performance before and after adjusted tuned

\begin{tabular}{|c|c|c|}
\hline Performance & (Block)Before tuned & (Tuned)After tuned \\
\hline Rise time, $\mathrm{Tr}$ & $0.662 \mathrm{sec}$ & $0.429 \mathrm{sec}$ \\
\hline Settling Time,Ts & $100 \mathrm{sec}$ & $3.89 \mathrm{sec}$ \\
\hline Overshoot,Os & $11.5 \%$ & $13.4 \%$ \\
\hline Close loop stability & Stable & Stable \\
\hline
\end{tabular}

Based on Table 2, it is not arguable that the after tuned performance has an acceptable performance to be implemented in this prosthetic hand research analysis. It offers fastest rise time (Tr), settling time (Ts), however, the percentage of overshoot is higher than the output response before tuned (block). Thus, the tuned PID Controller is preferable than block output response and this tuned output response have been decided to use as PID controller for this particular analysis [6]

Fig. 14 shown both of two systems with PID and without PID controller output response respectively. We can conclude that the with PID controller output response manage to meet the requirement stage during the design stage. By referring figure above, the rise time of without PID system performance dramatically increased compared with the with PID system. The increment then caused the output response of without PID system was not stable. Thus, PID controller manages to produce a good performance result and stabilized the prosthetic finger system.

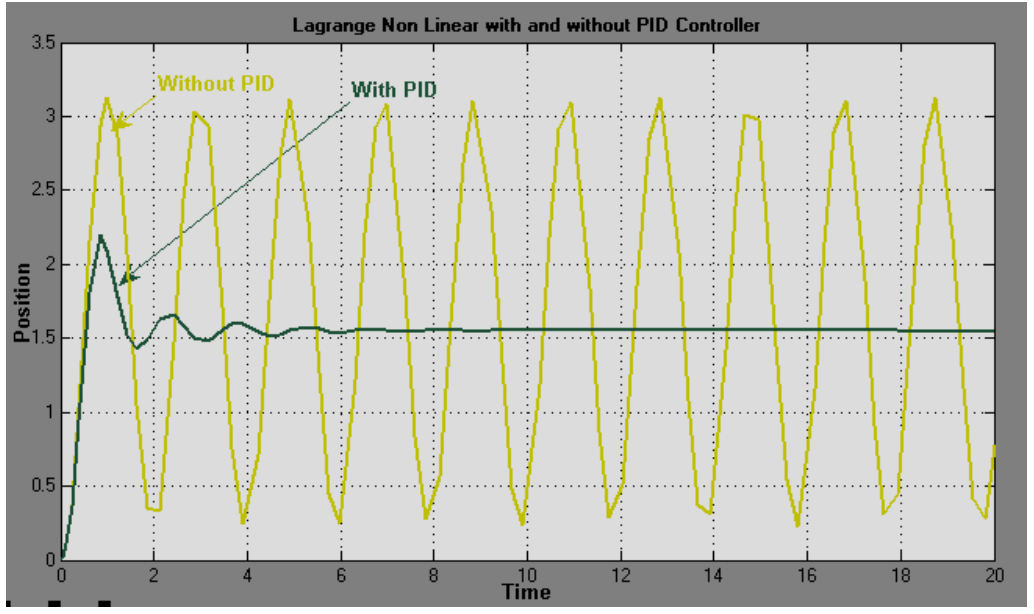

Fig. 14 Output response of with and without PID

\section{ConClusion AND Recommendation}

In conclusion, the unknown parameter value in this system can be estimated under certain condition which are the datasheet parameter and real data are required. It is because certain parameter not listed from the manufacturer. The analysis shows that the parameter estimation value produces a quite acceptable output response compare to the default value. Therefore, if any models that do not have complete parameter value in their manufacturer datasheet, parameter estimation technique can be performed.

\section{ACKNOWLEDGMENT}

The authors would like to thank Centre of Robotic and Industrial Automation (CeRIA) and Centre for Research and Innovation management (CRIM), Universiti Teknikal Malaysia Melaka (UTeM) and Ministry of Higher Education for financial assistant thru research grant.

\section{REFERENCES}

[1] Venkataraman, S.T. and Iderall, T., Dexterous Robot Hands, New York, NY: Springer-Verlag New York Inc., 1990, pp. 136-149.

[2] D. G. Smith, J. W. Michael, and J. H. Bowker, Atlas of Amputation and Limb Deficiencies - Surgical, Prosthetic, and Rehabilitation Principles: American Academyof Orthopaedic Surgeons, 2004

[3] Jones, L.: Dextrous hands: Human, prosthetic and robotic: A survey. Presence: Teleoperators and Virtual Environments. 6(1), 29-56 (1997)

[4] M.H.Jali, T.A.Izzuddin, R.Ghazali, N.E.S.Mustafa, H.I.Jaafar, H.Sarkawi, "System Identification Modeling of Arm Rehabilitation Devices", Journal of Theoretical and Applied Information Technology, vol. 81, no.3, pp 547-551, 2015.

[5] M.H.Jali, N.E.S.Mustafa, T.A.Izzuddin, R.Ghazali, H.I.Jaafar, “ ANFIS-PID Controller for Arm Rehabilitation Device”, International Journal of Engineering and Technology (IJET), vol 7, no 5, pp 1589-1597, 2015

[6] M.H.Jali, M.K.Alias, R.Ghazali, T.A.Izzuddin, H.I.Jaafar, "Development of Prosthethic Hand Hardware and Its Control System", International Journal of Soft Computing and Engineering (IJSCE), vol. 5, no. 5, pp. 28 -31, 2015 


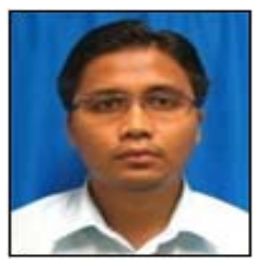

\section{AUTHOR PROFILE}

Mohd Hafiz bin Jali received the B.Sc. degree in electrical and electronic engineering with first class honors from MARA University of Technology, Malaysia in 2007 and completed his Master engineering studies with distinction in Industrial Electronics and Control at University of Malaya, Malaysia. He was with automotive company, Proton Sdn. Bhd from 2007 to 2010 as a Test Engineer under the Complete Vehicle Testing (CVT) department. In 2012, he was appointed as a Lecturer at Universiti Teknikal Malaysia Melaka, Malaysia. His research interests are in the general area of control, instrumentation and automation.

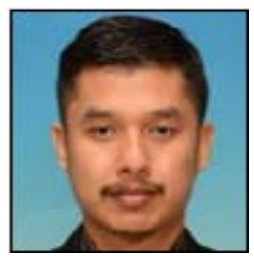

Rozaimi Ghazali, received his B.Eng degree in Electrical Engineering (instrumentation and Control) from Universiti Teknologi Malaysia (UTM), in 2008. He received the Ph. D in Electrical Engineering also from UTM, in 2013. Currently, he is a senior lecturer at Universiti Teknikal Malaysia Melaka (UTeM) and his interests are in system identification and robust controller design.

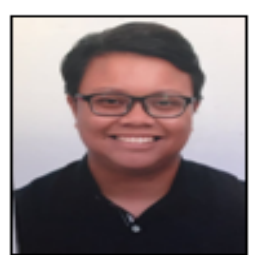

Ellyana Shaira Binti Abd Aziz, received her B. Eng. Tech. degree in Electronic Engineering (Industrial Electronic) from Universiti Teknikal Malaysia Melaka (UTeM) in 2015. Currently, she pursues her study in Master of Science on Electrical Engineering, UTeM. 